\title{
Clinical and Instrumental Exploration of Sensitive Skin in a Pediatric Population
}

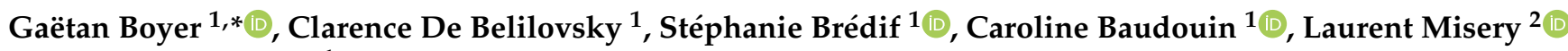 \\ and Gaëlle Bellemère ${ }^{1}$ \\ 1 Innovation R\&D Direction, Laboratoires Expanscience, Rue des 4 Filles, 28233 Epernon, France; \\ cdebelilovsky@expanscience.com (C.D.B.); sbredif@expanscience.com (S.B.); \\ cbaudouin@expanscience.com (C.B.); gbellemere@expanscience.com (G.B.) \\ 2 Department of Dermatology, University Hospital of Brest, 29609 Brest, France; laurent.misery@chu-brest.fr \\ * Correspondence: gboyer@expanscience.com; Tel.: +33-23-720-3626
}

check for updates

Citation: Boyer, G.; Belilovsky, C.D.; Brédif, S.; Baudouin, C.; Misery, L.; Bellemère, G. Clinical and Instrumental Exploration of Sensitive Skin in a Pediatric Population. Cosmetics 2021, 8, 43. https:// doi.org/10.3390/cosmetics8020043

Academic Editor: Maxim E. Darvin

Received: 12 February 2021

Accepted: 25 May 2021

Published: 30 May 2021

Publisher's Note: MDPI stays neutral with regard to jurisdictional claims in published maps and institutional affiliations.

Copyright: (c) 2021 by the authors. Licensee MDPI, Basel, Switzerland. This article is an open access article distributed under the terms and conditions of the Creative Commons Attribution (CC BY) license (https:// creativecommons.org/licenses/by/ $4.0 /)$.

\begin{abstract}
Studies on sensitive skin pathophysiology in infants are challenging because most assessment methods require self-reporting of signs. In this study, we aimed to identify and characterize sensitive skin in children for the first time. A newly developed parent-reported questionnaire was used to recruit children with sensitive skin. This questionnaire was also tested on an adult group. Hydration, transepidermal water loss (TEWL), and inflammatory markers (cytokines, and polyunsaturated fatty acids (PUFAs)) were quantified. A total of 77 children and 20 adults (33 and 10 with sensitive skin, respectively) were recruited. The groups with sensitive skin had more clinical signs of skin dryness. Skin hydration was lower in children in the sensitive compared with the nonsensitive skin group. TEWL levels were similar between sensitive and nonsensitive subjects in both infant and adult groups. Sensitive skin exhibited higher levels of cytokines and proinflammatory PUFAs as well as lower levels of anti-inflammatory PUFAs. Sensitive skin syndrome was associated with normal skin barrier function but lower hydration in infants and children. The higher levels of proinflammatory markers suggest that sensitive skin is associated with low-level inflammation. It is hypothesized, for the first time, that PUFAs are involved in sensitive skin syndrome in infants.
\end{abstract}

Keywords: pediatrics; sensitive skin syndrome; skin barrier; skin physiology/structure

\section{Introduction}

Sensitive skin is a syndrome defined by "the occurrence of unpleasant sensations in response to stimuli that normally should not provoke such sensations" [1]. Among the triggering factors, environmental (e.g., heat or cold), physical (e.g., textiles), and chemical (e.g., cosmetics or detergents) factors have been shown to provoke sensitive skin reactions [2-4]. Clinically, sensitive skin syndrome is mostly characterized by objective skin signs, such as skin redness, as well as by a number of perceived and subjective sensations, such as stinging, burning, pain, pruritus, and tingling sensations [1]. The determination of sensitive skin syndrome is mainly reliant on patient self-diagnosis [5]. To date, only a few questionnaires for the evaluation of sensitive skin syndrome have been developed [6,7].

While the physiology of sensitive skin in adults remains unclear, this syndrome has been associated with impaired skin barrier function [8,9] in a number of studies, while this association was not identified in others $[10,11]$. Similarly, some studies observed a lower hydration level in the skin of subjects with sensitive skin under basal conditions [12,13], whereas others did not [10,11]. A recent study performed using confocal Raman spectroscopy did not discover any alterations in the skin barrier of sensitive skin in terms of stratum thickness, water, natural moisturizing factors (NMFs), or ceramide/fatty-acid content [14].

In addition to skin barrier function, other factors, such as changes in the cutaneous sensory system, may play a role in sensitive skin syndrome. The intraepidermal nerve C fiber density is lower in subjects with sensitive skin [15], and the expression of transient 
receptor potential vanilloid-1 (TRPV1) is upregulated in subjects with sensitive skin [16]. The inhibition of this receptor successfully reduced capsaicin-induced burning in women sensitive to capsaicin [17]. Notably, activation of TRPV1 increased the expression of inflammatory cytokine interleukin 8 (IL-8) [18]. In a previous study; however, no differences in inflammatory markers were observed between nonsensitive and sensitive skin [15], whereas another study observed higher levels of prostaglandin E2 in sensitive skin [19]. Despite the focus on elucidating the underlying causes of sensitive skin in adults, no factors have been unequivocally linked to its pathophysiology.

Reports describing sensitive skin in children, particularly in infants, are extremely scarce, and the biometrologic characteristics of sensitive skin in infants and children have never been studied. Such studies of sensitive skin in infants and children are challenging. The first hurdle is to secure the enrollment of infants and children with genuine cases of sensitive skin. Sensitive skin syndrome is associated with subjective sensations that cannot be reported or described by infants or children. Therefore, any identification of sensitive skin syndrome in children has to be based on parent observations, which leads to potential bias or over-/misdeclaration. Another difficulty is the characterization of sensitive skin syndrome in infants and children, considering that biomarkers have not yet been identified in adult populations. Lastly, another challenge is the need to perform noninvasive clinical investigations, due to obvious ethical reasons.

In order to study sensitive skin in infants and children, we sought (i) to develop a parent-reported questionnaire designed to identify sensitive skin in children on the basis of skin reactions to previously described triggering factors [20], (ii) to recruit children using this newly developed questionnaire, (iii) to recruit adults with sensitive or nonsensitive skin in order to validate the questionnaire, and (iv) to perform noninvasive evaluations in both children and adults in order to identify and validate biomarkers of sensitive skin. As sensitive skin syndrome has been associated with skin hydration and barrier function variations, we measured skin hydration, TEWL (transepidermal water loss), NMFs, and ceramides and performed clinical scoring of dry skin. As sensitive skin syndrome has also been linked to inflammation pathways, some biomarkers of skin inflammation, such as IL-1 $\alpha$, IL-1 receptor antagonist (IL-1 RA), IL-8, and polyunsaturated fatty acids (PUFAs), were also measured in the subjects.

\section{Materials and Methods}

\subsection{Questionnaire for Identification of Sensitive Skin in Children}

We previously performed an epidemiological study including more than 8000 subjects across five countries, where we showed that approximately $30 \%$ of children are described as having sensitive skin by their parents. In this study, the triggers of skin sensitivity could be grouped into three categories of environmental, mechanical, and external factors [20]. In order to recruit children with sensitive skin, we developed a new parent-reported questionnaire based on skin reactions induced by the triggers that we had previously documented [2-4]. The parents were asked to document whether the skin reaction was objective (e.g., redness) or subjective (e.g., itch, burning, or prickling). The child was reported as having sensitive skin syndrome if the parent described skin reactions due to at least two factors. On the contrary, a child was considered to have nonsensitive skin if no skin reaction was reported for any trigger (Figure 1). Details of the counts per trigger for the sensitive skin panel are presented in Appendix Figure A1. The included subjects were healthy with phototype I-III. Subjects with diagnosed atopic dermatitis were excluded from both nonsensitive and sensitive groups as an association of $\mathrm{AD}$ with sensitive skin characteristics could exist and interfere with the evaluated parameters [21,22]. 


\begin{tabular}{|c|c|c|c|}
\hline & Trigger & Objective reaction? yes/no & Subjective reaction? yes/no \\
\hline \multirow{6}{*}{ 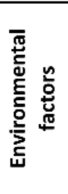 } & Cold & & \\
\hline & Hot & & \\
\hline & Quick temperature variation & & \\
\hline & Wind & & \\
\hline & Humidity & & \\
\hline & Pollution & & \\
\hline
\end{tabular}

\begin{tabular}{|c|c|c|c|}
\hline & Trigger & Objective reaction? yes/no & Subjective reaction? yes/no \\
\hline \multirow{7}{*}{ 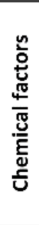 } & Hygiene products & & \\
\hline & Care products & & \\
\hline & Normal water & & \\
\hline & Hard water & & \\
\hline & Chlorinated water & & \\
\hline & Laundry detergent / softener & & \\
\hline & Fragrance & & \\
\hline & & $A=$ Sum of yes & B = Sum of yes \\
\hline
\end{tabular}

\begin{tabular}{|c|c|c|c|}
\hline & Trigger & Objective reaction? yes/no & Subjective reaction? yes/no \\
\hline \multirow{8}{*}{ 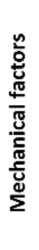 } & Father's beard & & \\
\hline & Wool clothes & & \\
\hline & Cotton clothes & & \\
\hline & Linen clothes & & \\
\hline & Silk clothes & & \\
\hline & Viscose clothes & & \\
\hline & Synthetic materials & & \\
\hline & Other materials & & \\
\hline & & $A=$ Sum of yes & B = Sum of yes \\
\hline
\end{tabular}

Sensitive or nonsensitive skin classification rules:

For each factor, if $A \geq 1$ or $B \geq 2$, the subject is considered as sensitive to the factor.

If the subject is sensitive to at least 2 factors, the subject is considered as presenting sensitive skin.

If no skin reaction is reported for any factor, the subject is considered as having nonsensitive skin.

Figure 1. Questionnaire for the identification of children with sensitive or nonsensitive skin.

\subsection{Clinical Evaluations}

The study was conducted in Poland under dermatological control from March to May 2016. All measurements were performed on face skin. All evaluations were completely noninvasive. Written informed consent was obtained for each subject enrolled in the study. The study was conducted according to the guidelines of the Declaration of Helsinki following Good Clinical Practice. Ethical review and approval by an independent IRB were waived for this study due to the noninvasive methods used; as such, this study was reviewed by an internal institutional review board.

Dryness of the skin was evaluated clinically on the face using the specified symptom sum score of scaling, roughness, redness, and cracks (SRRC) [23]. This score corresponds to the sum of four characteristics (scaling, roughness, redness, and cracks) and includes five grades for each characteristic (from $0=$ absent to $4=$ extreme). We considered both the whole score and the score for scaling, roughness, and redness characteristics.

\subsection{Instrumental Assessment}

Hydration and TEWL measurements were performed on the cheek using a Corneometer CM825 device (Courage and Khazaka, Köln, Germany) and an Aquaflux AF 200 device (Biox System Ltd., London, UK, closed chamber method).

\subsection{Quantification of Biological Markers in Skin Surface Samples}

Interleukin- $1 \alpha$ (IL-1 $\alpha)$, IL-1RA, and IL- 8 were extracted from swabs collected from the cheek using two swab kits (one for interleukins and one for PUFAs). Each kit contained two sterile cotton swabs and $500 \mu \mathrm{L}$ of sampling cocktail buffer (Synelvia proprietary information: a mixture of surfactants/chelating agents) in an Eppendorf tube. Cotton swabs were wetted by soaking the swab in cocktail buffer. The swab was then gently applied to the skin surface delimited by a provided template. Pressure was applied, and the swab was moved over the whole skin test area $\left(5 \mathrm{~cm}^{2}\right)$ for $45 \mathrm{~s}$. The swab was cut with 
scissors and placed into the Eppendorf tube. This procedure was repeated with the second swab, which was then placed in the same Eppendorf tube. Samples were stored directly on wet ice and stored in $\mathrm{a}-20^{\circ} \mathrm{C}$ freezer within $2 \mathrm{~h}$ of sampling and shipped on dry ice to Synelvia SAS (Toulouse, France) for analysis. After a 30 min sonication, the cytokines were quantified using specific enzyme-linked immunosorbent assay (ELISA) kits (R\&D Systems Inc., Minneapolis, MN, USA). Total protein level was used for normalization of each cytokine. For determination of total protein, the Protein Assay BCA Kit (Bio Basic Inc.) was used. The BCA kit uses a bicinchoninic acid (BCA) formulation, which enables the detection and quantification of proteins in an alkaline medium, whereby proteins reduce $\mathrm{Cu}^{2+}$ to $\mathrm{Cu}^{+}$. The detected $\mathrm{Cu}^{+}$reacts with two molecules of $\mathrm{BCA}$, leading to a colored complex which is analyzed at $562 \mathrm{~nm}$.

Polyunsaturated fatty acids were extracted from the swabs using a chloroform/ methanol solution for $1 \mathrm{~h}$ at ambient temperature. The organic fraction was washed using a buffer solution, and the lipidic fraction was methylated. The PUFAs were then analyzed using gas chromatography (Agilent 7890A gas chromatograph, Agilent Technologies Inc., Santa Clara, USA) coupled to mass spectrometry (Agilent 5975C mass spectrometer, Agilent Technologies Inc., Santa Clara, USA). The following PUFA species were quantified: linoleic acid (C18:2), arachidonic acid (C20:4), eicosapentaenoic acid (C20:5), docosahexaenoic acid (C22:6), and palmitic acid (C16:0), the latter of which was used for normalization. Because palmitic acid is the main constituent of sebum, this fatty acid was used as an internal standard for the normalization of the concentration of PUFA in the biological samples collected. Actually, on the skin surface, PUFAs are soluble in sebum and are most probably collected with sebum by the swab technique used in our study. Although palmitic acid has recently been considered as a signal molecule involved in inflammatory processes in acne, we did not observe any variation of the levels of palmitic acid between sensitive and nonsensitive groups, demonstrating that palmitic may not be involved in sensitive skin syndrome.

\subsection{Statistical Analysis}

Statistical analysis was performed using R software version 3.6.1 [24]. Normality of the data was tested using a Shapiro-Wilk test, whereas a Wilcoxon test or Student's $t$-test was used to assess the statistical significance of differences between nonsensitive and sensitive skin groups for both children and adults groups. $p<0.05$ was considered to indicate statistically significant differences. Histograms represent the mean \pm standard deviation.

\section{Results}

A total of 77 children aged three to 48 months were recruited. Of these, 44 subjects (26 females and 18 males) had nonsensitive skin, and 33 subjects ( 15 females and 18 males) had sensitive skin. In addition, adults aged $18-20$ years (10 subjects with nonsensitive skin (six women and four men) and 10 subjects with sensitive skin (six women and four men)) were recruited in order to validate the questionnaire for discrimination of sensitive skin from nonsensitive skin.

Differences in SRRC scores between sensitive and nonsensitive skin groups were observed. The global score (sum of the four characteristics) indicated that subjects in the sensitive skin group had more skin dryness than the nonsensitive skin group for both children and adults ( $p<0.001$ for each group, Figure 2A). The children in the sensitive skin group had more scaling $(p<0.001$, Figure 2B), roughness $(p<0.001$, Figure 2C), and redness $(p<0.001$, Figure 2D) than those in the nonsensitive skin group. Similar results were observed for the adults with sensitive skin regarding roughness $(p<0.001$, Figure 2C) and redness $(p<0.01$, Figure 2D). Cracks in the skin were virtually absent in both skin types and in both age groups. 

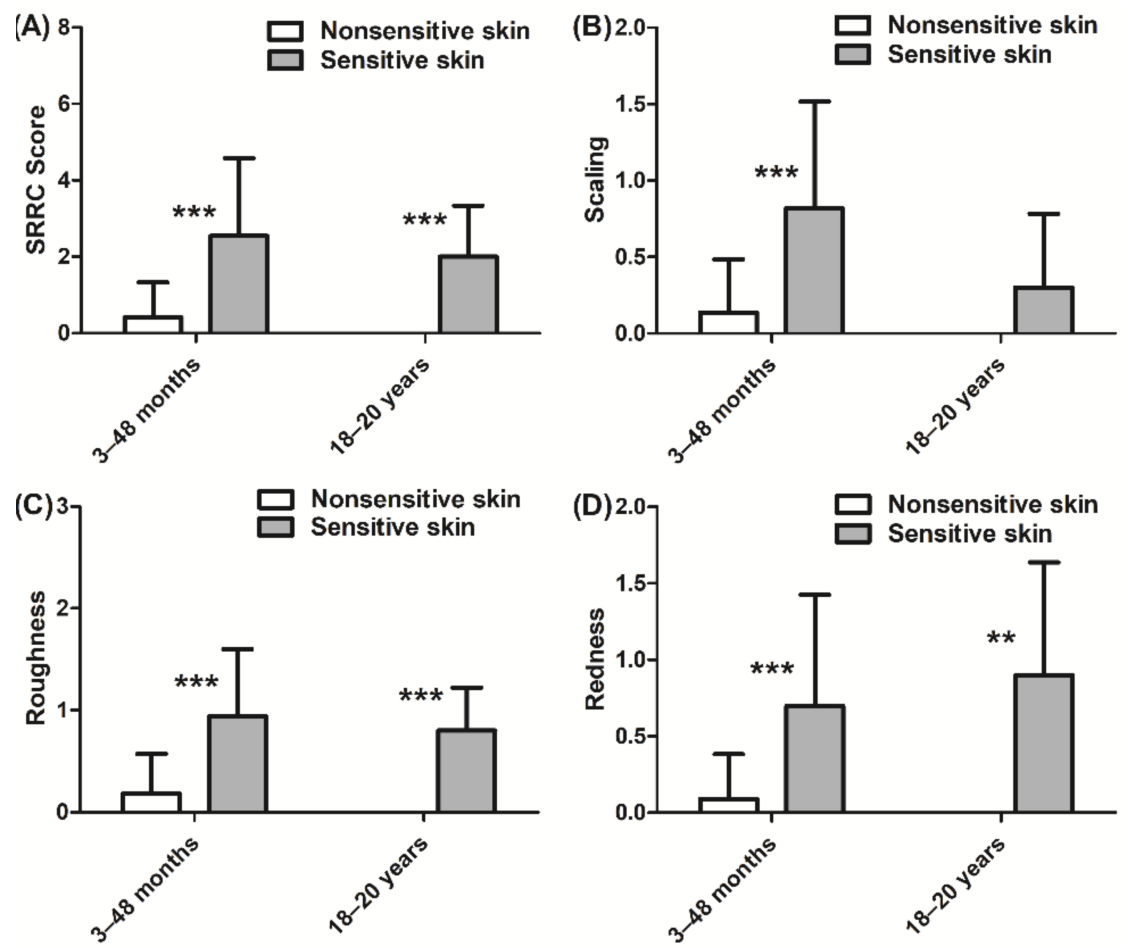

Figure 2. Clinical evaluation of nonsensitive and sensitive skin dryness according to SRRC (scaling, roughness, redness, and cracks) scores: (A) total SRRC score; (B) scaling score; (C) roughness score; (D) redness score. Scaling, roughness, and redness were absent in the nonsensitive skin group aged 18-20 years. Data are shown as the mean \pm SD of all subjects in the group. ${ }^{* *} p<0.01,{ }^{* * *} p<0.001$.

In children, hydration was lower $(-21 \%, p<0.01$, Figure $3 \mathrm{~A})$ in the sensitive skin group than in the nonsensitive skin group. By contrast, no significant difference in hydration was observed in adults. Furthermore, the barrier function, which was assessed via measurement of TEWL, was not different between the sensitive skin and nonsensitive skin groups in either children or adults (Figure 3B).
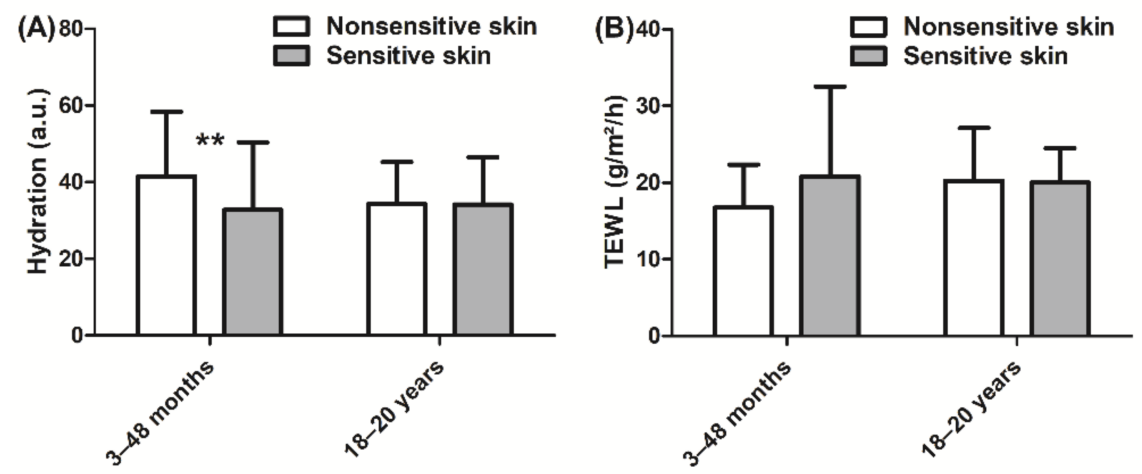

Figure 3. (A) Hydration measurement using a Corneometer and (B) TEWL (transepidermal water loss) measurement using an Aquaflux. Data are shown as the mean $\pm \mathrm{SD}$ of all subjects in the group. ** $p<0.01$. 
In addition, we also assessed the inflammatory state of the skin via quantitation of cytokine and PUFA expression. Children with sensitive skin presented higher levels of IL-1 $\alpha$, IL-1RA, and IL-8 $(+127 \%,+131 \%$, and $+98 \%$, respectively, $p<0.001$; Figure 4 A-C) than those with nonsensitive skin. Similar levels of cytokine expression were observed in adult subjects with sensitive skin. In adults, the ratio of IL-1RA/IL- $1 \alpha$ was higher in those with sensitive skin than in those with nonsensitive skin $(+41 \%, p<0.001$; Figure 4D). Children with sensitive skin also exhibited higher levels of linoleic acid $(+13 \%, p<0.001$; Figure $5 \mathrm{~A})$ and arachidonic acid $(+20 \%, p<0.001$; Figure $5 \mathrm{~B})$, which are both proinflammatory biomarkers, than those with nonsensitive skin. Levels of anti-inflammatory PUFAs were decreased (eicosapentaenoic acid and docosahexaenoic acid, $-14 \%$ and $-20 \%$, respectively, $p<0.05$ and $p<0.001$; Figure 5C,D) in children with sensitive skin compared to those with nonsensitive skin. Results of the adult group were quite similar. More specifically, the adult sensitive skin group had higher levels of the proinflammatory biomarkers linoleic acid $(+28 \%, p<0.001$; Figure 5A) and arachidonic acid $(+51 \%, p<0.001$; Figure 5B) and lower levels of the anti-inflammatory element eicosapentaenoic acid $(-38 \%, p<0.001$; Figure 5C) than the nonsensitive skin group.

No age dependence was observed with respect to the measured parameters for children.
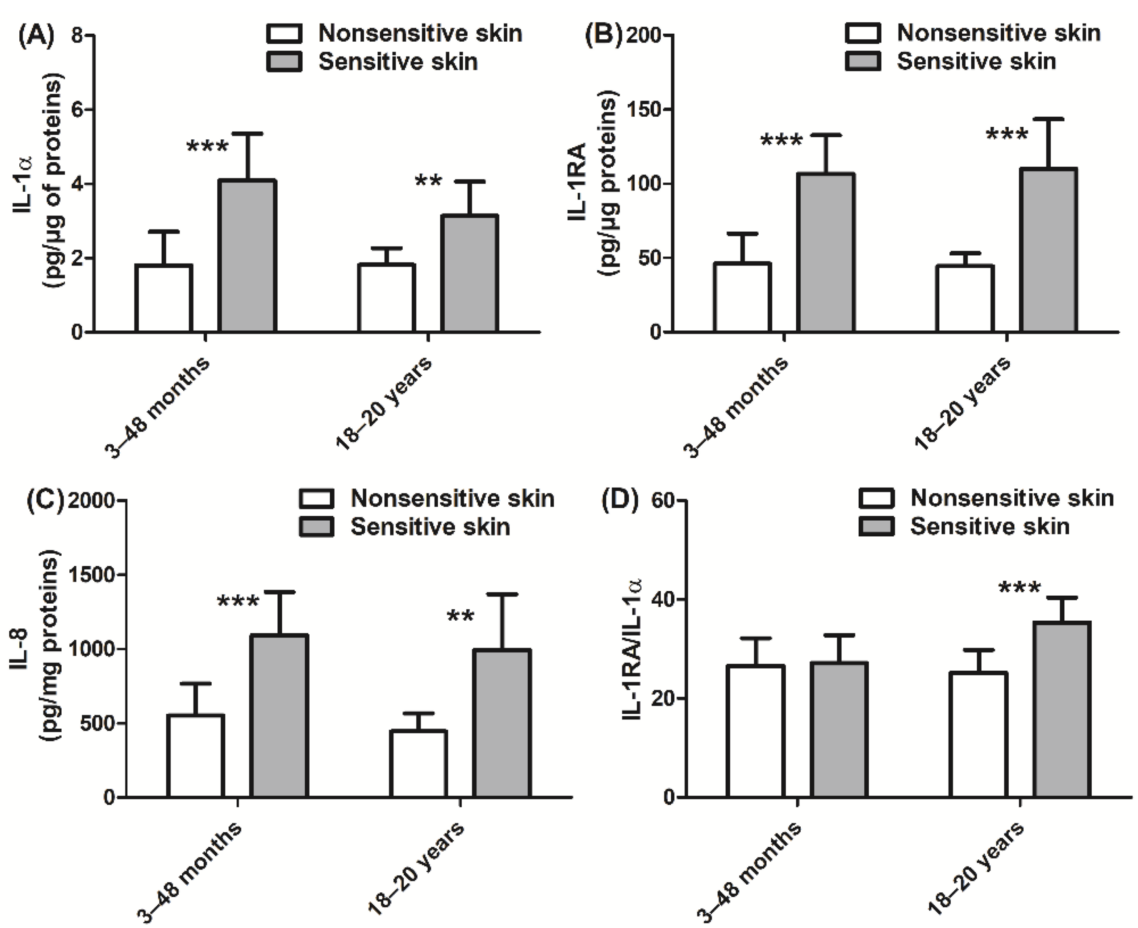

Figure 4. Quantification of cytokines: (A) IL-1 $\alpha$; (B) IL-1RA; (C) IL-8; (D) IL-1RA/IL-1 $\alpha$ ratio. Data are shown as the mean $\pm \mathrm{SD}$ of all subjects in the group. ${ }^{* *} p<0.01,{ }^{* * *} p<0.001$. 

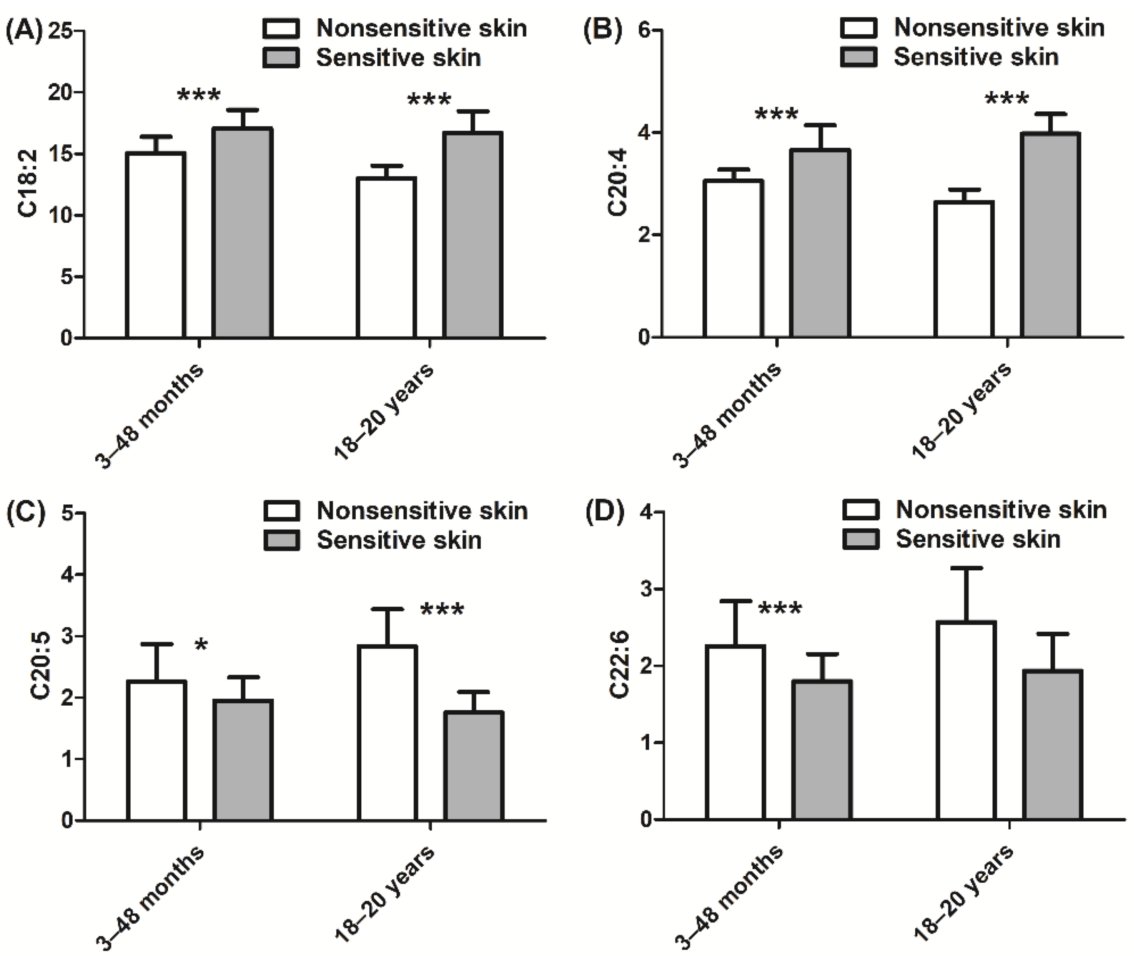

Figure 5. Quantification of PUFAs (polyunsaturated fatty acids): (A) C18:2 linoleic acid; (B) C20:4 arachidonic acid; (C) C20:5 eicosapentaenoic acid; (D) C22:6 docosahexaenoic acid. Data are shown as the mean $\pm \mathrm{SD}$ of all subjects in the group. ${ }^{*} p<0.05,{ }^{* * *} p<0.001$.

\section{Discussion}

In order to study the biometrological characteristics of sensitive skin in infants, it was crucial to first develop a questionnaire for the identification of sensitive skin in children. As questionnaires developed in adults [6,7] are not transposable to infants, we developed a new questionnaire, which was designed for the identification of sensitive skin in infants according to the parent description of skin reactions to multiple triggers grouped into three main categories (environmental, mechanical, and chemical factors). Objective skin reactions, such as redness, and general subjective signs, such as unpleasant sensation perceived by the child, were considered. Questionnaires for the recruitment of the children were addressed to the parents who gave answers according to the observation of objective signs of their child's skin and according to the observations of the behavior of their child for subjective signs regardless of the child's age. Older children are able to verbally communicate subjective reactions, making it easier for the parents to understand their feelings concerning the different triggers. A recent paper concluded that it is essential to gain a full assessment of the associated symptoms and to select subjects on the basis of skin reactions to multiple triggers in order to most accurately study the pathophysiology of sensitive skin [7]. Therefore, subjects for this study were considered to have sensitive skin when they reported a reaction to at least two factors, with at least one objective sign or two subjective signs. The intensity and duration of objective reactions, such as redness, were not taken into account for subject inclusion, but they can be studied in future work to determine the severity of skin sensitivity. In order to further evaluate this new questionnaire, we also recruited adults with sensitive skin for this study. The adult group was quite young and may not be representative of adults in general. Differences with age could exist in adults in terms of measured parameters; thus, we chose to restrict the age scale for this group to 18 to 20 years to avoid group heterogeneity. Moreover, the adult panel was quite small in our study, and future work should supplement the obtained data to strengthen the questionnaire's validation.

Global analysis indicated that the infants identified by the questionnaire share some common characteristics, such as cytokine biomarkers, with adults who reported having 
sensitive skin according to the results of the questionnaire. This finding demonstrates that the questionnaire, which is based on triggering factors of stress, can identify infants that most likely present with sensitive skin syndrome.

Recent studies indicate that levels of proinflammatory mediators are not modified in sensitive skin [15]. In the present work, we observed an imbalance in the expression of inflammation markers on the skin surface in the absence of specific stimuli. In particular, in infants and adults, increased levels of cytokines IL- $1 \alpha$, IL-1RA, and IL- 8 and an increased IL-1RA/IL- $1 \alpha$ ratio only in adults were noted. IL- $1 \alpha$ is a cytokine activated by classic damage-associated molecular patterns (DAMPs) and functions as an "alarmin" [25]. IL-1 $\alpha$ is released in response to various stimuli, and large amounts of IL- $1 \alpha$ are found in the epidermis [26]. In addition, this cytokine has been reported to induce the expression of antimicrobial peptides [27] in keratinocytes and to promote expression of chemokines, such as IL-8 [28]. Keratinocytes produce not only IL-1 $\alpha$ but also the receptor antagonist IL1RA [29]. An appropriate balance between IL-1 $\alpha$ and IL-1RA helps to maintain homeostasis and to regulate inflammation $[29,30]$. An elevated IL-1RA/IL-1 $\alpha$ ratio was reported in inflammatory skin diseases [31] and subsequent stress [29-32]. Lastly, IL-8, which is a chemokine that mediates the recruitment of neutrophils [33], is involved in various inflammatory diseases, such as psoriasis [34].

Our results also show that PUFA composition is modified in sensitive skin in the absence of any stimuli. Polyunsaturated fatty acids are omega fatty acids that play a critical role in many skin functions. The involvement of PUFAs in skin inflammation is still not clear. Some omega- 6 fatty acids, such as linoleic acid, are considered pro-inflammatory but their context in inflammation is complex and still not properly understood [35-38]. Some skin diseases, such as atopic dermatitis or psoriasis, have been found to be associated with the modification of PUFA composition in some studies, whereas other findings did not provide evidence that PUFAs have a specific pattern in atopy [39-41]. It is generally accepted that PUFAs are metabolized as signaling mediators involved in inflammatory processes [42]. In particular, eicosapentaenoic acid and docosahexaenoic acid are omega-3 fatty acids generally considered as anti-inflammatory mediators [43,44], whereas linoleic acid and arachidonic acid are omega- 6 fatty acids generally associated with proinflammatory responses [35]. Interestingly, in sensitive skin, both in children and in adults, we observed higher levels of linoleic and arachidonic acids that are considered proinflammatory, and lower levels of eicosapentaenoic and docosahexaenoic acids that present anti-inflammatory activity.

Collectively, our data indicate that infants with sensitive skin syndrome present, without any specific stimuli, elevated levels of inflammatory mediators in the absence of any clinical manifestation of skin inflammation. This typical state of skin inflammation, with molecular modifications in the absence of clinical manifestation, has been identified as subclinical inflammation, as reviewed by Stamatas et al. in 2013 [45]. We show that sensitive skin in infants presented elevated levels of cytokines related to innate immunity, which may play a pivotal role in the subclinical inflammation of the skin [45]. Thus, we hypothesize that, in sensitive skin subjects, skin inflammation is more easily triggered by external factors than in nonsensitive skin subjects due to the presence of silent subclinical inflammation in their skin.

Low levels of stratum corneum hydration were found in children with sensitive skin compared to those with nonsensitive skin, while TEWL values were similar between the two groups of children. These findings suggest that a decrease in stratum corneum hydration may be due to the decreased water-holding capacity of the skin rather than to alterations of barrier function. Interestingly, we further showed that levels of hygroscopic NMFs and ceramide were not different between sensitive and nonsensitive skin in infants or adults (data not shown). These results suggest that sensitive skin syndrome may not be associated with typical biochemical parameters of dry skin, in agreement with previous results [14]. The alteration of skin barrier function, often associated with sensitive skin syndrome, may involve additional mechanisms that were not investigated in the present 
study. Such mechanisms may include disorganization of the structure of the intercellular lamellar lipid or decreased stratum corneum cohesion in sensitive skin.

A clinical evaluation of sensitive skin showed that sensitive skin presents more erythema than nonsensitive skin, consistent with the higher inflammatory marker levels observed in sensitive skin in our study. We also show that sensitive skin presents greater levels of scaling and roughness than nonsensitive skin, in line with our hypothesis that sensitive skin may stem from altered stratum corneum and corneocyte cohesion, which leads to a subtle imbalance in the regulation of water homeostasis in sensitive skin. Altered cohesion of corneocytes may lead to a misdiagnosis of dry skin instead of sensitive skin syndrome, particularly in infants. We previously demonstrated that low corneocyte cohesion, altered corneocyte morphology, and increased desquamation are related to skin immaturity in infants [46]. These same clinical hallmarks may actually also be present in sensitive skin, but additional work is needed to further test this hypothesis.

\section{Conclusions}

Here, we presented the results of a study examining sensitive skin in children and reported differences between sensitive skin and nonsensitive skin in this pediatric population. Our data indicate that sensitive skin syndrome is associated with silent inflammation levels and with nearly normal skin barrier function. Furthermore, while hydration was lower in infants with sensitive skin, TEWL was virtually normal in these individuals. According to these findings, we further hypothesize that sensitive skin syndrome is associated with impaired skin maturation and desquamation, particularly in infants.

Author Contributions: G.B. (Gaëtan Boyer), C.D.B., S.B., C.B., and G.B. (Gaëlle Bellemère) contributed to supervision, realization, writing, and reviewing of the study. L.M. contributed to supervision, writing, and reviewing of the study. All authors read and agreed to the published version of the manuscript.

Funding: This research received no external funding.

Institutional Review Board Statement: The study was conducted according to the guidelines of the Declaration of Helsinki following Good Clinical Practice. Ethical review and approval by an independent IRB were waived for this study due to the noninvasive methods used; as such, this study was re-viewed by an internal institutional review board.

Informed Consent Statement: Informed consent was obtained from all subjects involved in the study.

Data Availability Statement: The data presented in this study are available on request from the corresponding author. The data are not publicly available due to privacy reasons.

Acknowledgments: The authors thank Bernard Chadoutaud (ClinReal OnLine) for support with the clinical study, Alain Moga (Synelvia) for expert support with biomarker bioanalysis, and BioScience Writers for expert review and editing of the manuscript.

Conflicts of Interest: G.B., C.D.B., S.B., C.B., and G.B. are Laboratoires Expanscience employees. L.M. is a consultant of Laboratoires Expanscience. 


\section{Appendix A}

\begin{tabular}{|c|c|c|c|c|c|c|c|}
\hline \multirow{7}{*}{ 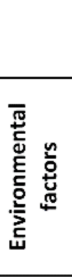 } & Trigger & \multicolumn{3}{|c|}{$\begin{array}{l}\% \text { of objective reactions } \\
\text { [children - adults] }\end{array}$} & \multicolumn{3}{|c|}{$\begin{array}{l}\% \text { of subjective reactions } \\
\text { [children - adults] }\end{array}$} \\
\hline & Cold & $75.8 \%$ & - & $90 \%$ & $69.7 \%$ & - & $80 \%$ \\
\hline & Hot & $75.8 \%$ & - & $50 \%$ & $72.7 \%$ & - & $50 \%$ \\
\hline & Quick temperature variation & $54.5 \%$ & - & $20 \%$ & $54.5 \%$ & - & $20 \%$ \\
\hline & Wind & $66.7 \%$ & - & $20 \%$ & $66.7 \%$ & - & $20 \%$ \\
\hline & Humidity & $6.1 \%$ & - & $10 \%$ & $6.1 \%$ & - & $10 \%$ \\
\hline & Pollution & $21.2 \%$ & - & $10 \%$ & $21.2 \%$ & - & $10 \%$ \\
\hline \multirow{7}{*}{ 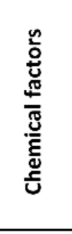 } & Hygiene products & $42.4 \%$ & - & $90 \%$ & $42.4 \%$ & - & $90 \%$ \\
\hline & Care products & $39.4 \%$ & - & $50 \%$ & $36.4 \%$ & - & $50 \%$ \\
\hline & Normal water & $24.2 \%$ & - & $30 \%$ & $24.2 \%$ & - & $30 \%$ \\
\hline & Hard water & $36.4 \%$ & - & $60 \%$ & $36.4 \%$ & - & $60 \%$ \\
\hline & Chlorinated water & $21.2 \%$ & - & $60 \%$ & $21.2 \%$ & - & $60 \%$ \\
\hline & Laundry detergent / softener & $33.3 \%$ & - & $20 \%$ & $33.3 \%$ & - & $20 \%$ \\
\hline & Fragrance & $15.2 \%$ & - & $0 \%$ & $12.1 \%$ & - & $0 \%$ \\
\hline \multirow{8}{*}{ 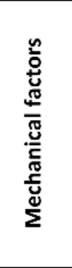 } & Father's beard & $57.6 \%$ & - & $40 \%$ & $54.5 \%$ & - & $40 \%$ \\
\hline & Wool clothes & $15.2 \%$ & - & $30 \%$ & $15.2 \%$ & - & $30 \%$ \\
\hline & Cotton clothes & $3 \%$ & - & $0 \%$ & $3 \%$ & - & $0 \%$ \\
\hline & \begin{tabular}{|l|} 
Linen clothes \\
\end{tabular} & $0 \%$ & - & $20 \%$ & $0 \%$ & - & $20 \%$ \\
\hline & Silk clothes & $0 \%$ & - & $0 \%$ & $0 \%$ & - & $0 \%$ \\
\hline & \begin{tabular}{|l|} 
Viscose clothes \\
\end{tabular} & $15.2 \%$ & - & $20 \%$ & $15.2 \%$ & - & $20 \%$ \\
\hline & Synthetic materials & $30.3 \%$ & - & $20 \%$ & $30.3 \%$ & - & $20 \%$ \\
\hline & Other materials & $0 \%$ & - & $0 \%$ & $0 \%$ & - & $0 \%$ \\
\hline
\end{tabular}

Figure A1. Percentage of objective and subjective reactions to each trigger for child and adult groups.

\section{References}

1. Misery, L.; Ständer, S.; Szepietowski, J.; Reich, A.; Wallengren, J.; Evers, A.; Takamori, K.; Brenaut, E.; Gall-Ianotto, C.; Fluhr, J.; et al. Definition of Sensitive Skin: An Expert Position Paper from the Special Interest Group on Sensitive Skin of the International Forum for the Study of Itch. Acta Derm. Venereol. 2017, 97, 4-6. [CrossRef] [PubMed]

2. Sparavigna, A.; Di Pietro, A.; Setaro, M. 'Healthy skin': Significance and results of an Italian study on healthy population with particular regard to 'sensitive' skin. Int. J. Cosmet. Sci. 2005, 27, 327-331. [CrossRef]

3. Saint-Martory, C.; Roguedas-Contios, A.; Sibaud, V.; Degouy, A.; Schmitt, A.; Misery, L. Sensitive skin is not limited to the face. Br. J. Dermatol. 2007, 158, 130-133. [CrossRef]

4. Brenaut, E.; Barnetche, T.; Ianotto, C.L.; Roudot, A.; Misery, L.; Ficheux, A. Triggering factors in sensitive skin from the worldwide patients' point of view: A systematic literature review and meta-analysis. J. Eur. Acad. Dermatol. Venereol. 2019, 34, 230-238. [CrossRef] [PubMed]

5. Bowman, J.P.; Znaniecki, A.; Kligman, A.M.; Stoudemayer, T.; Mills, O.H. The use of chemical probes to assess the facial reactivity of women, comparing their self-perception and sensitive skin. J. Cosmet. Sci. 2000, 51, 267-273.

6. Misery, L.; Jean-Decoster, C.; Mery, S.; Georgescu, V.; Sibaud, V. A New Ten-Item Questionnaire for Assessing Sensitive Skin: The Sensitive Scale-10. Acta Derm. Venereol. 2014, 94, 635-639. [CrossRef]

7. Richters, R.; Uzunbajakava, N.; Hendriks, J.; Bikker, J.W.; Van Erp, P.; Van De Kerkhof, P. A model for perception-based identification of sensitive skin. J. Eur. Acad. Dermatol. Venereol. 2016, 31, 267-273. [CrossRef] [PubMed]

8. Distante, F.; Rigano, L.; D'Agostino, R.; Bonfigli, A.; Berardesca, E. Intra- and Inter-Individual Differences in Sensitive Skin. Cosmet. Toilet. 2002, 117, 39-46.

9. Pinto, P.; Rosado, C.; Parreirão, C.; Rodrigues, L.M. Is there any barrier impairment in sensitive skin? A quantitative analysis of sensitive skin by mathematical modeling of transepidermal water loss desorption curves. Skin Res. Technol. 2011, 17, 181-185. [CrossRef]

10. Löffler, H.D.H.; Dickel, H.; Kuss, O.; Diepgen, T.L.; Effendy, I. Characteristics of Self-estimated Enhanced Skin Susceptibility. Acta Derm. Venereol. 2001, 81, 343-346. [CrossRef] [PubMed]

11. Diogo, L.; Papoila, A.L. Is it possible to characterize objectively sensitive skin? Skin Res. Technol. 2010, 16, 30-37. [CrossRef] [PubMed]

12. Roussaki-Schulze, A.V.; Afiriou, E.; Nikoulis, D.; Klimi, E.; Rallis, E.; Zintzaras, E. Objective biophysical findings in patients with sensitive skin. Drugs Exp. Clin. Res. 2005, 31, 17-24.

13. Seidenari, S.; Francomano, M.; Mantovani, L. Baseline biophysical parameters in subjects with sensitive skin. Contact Dermat. 1998, 38, 311-315. [CrossRef] [PubMed]

14. Richters, R.J.; Falcone, D.; Uzunbajakava, N.E.; Varghese, B.; Caspers, P.J.; Puppels, G.J.; Van Erp, P.E.; Van De Kerkhof, P.C. Sensitive Skin: Assessment of the Skin Barrier Using Confocal Raman Microspectroscopy. Skin Pharmacol. Physiol. 2017, 30, 1-12. [CrossRef] [PubMed] 
15. Buhé, V.; Vie, K.; Guéré, C.; Natalizio, A.; Lhéritier, C.; Gall-Ianotto, C.; Huet, F.; Talagas, M.; Lebonvallet, N.; Marcorelles, P.; et al. Pathophysiological Study of Sensitive Skin. Acta Derm. Venereol. 2016, 96, 314-318. [CrossRef]

16. Ehnis-Pérez, A.; Torres-Alvarez, B.; Cortés-García, D.; Hernandez-Blanco, D.; Fuentes-Ahumada, C.; Castanedo-Cázares, J.P. Relationship between transient receptor potential vanilloid-1 expression and the intensity of sensitive skin symptoms. J. Cosmet. Dermatol. 2015, 15, 231-237. [CrossRef] [PubMed]

17. Kueper, T.; Krohn, M.; Haustedt, L.O.; Hatt, H.; Schmaus, G.; Vielhaber, G. Inhibition of TRPV1 for the treatment of sensitive skin. Exp. Dermatol. 2010, 19, 980-986. [CrossRef]

18. Fernandes, E.S.; Fernandes, M.; E Keeble, J. The functions of TRPA1 and TRPV1: Moving away from sensory nerves. Br. J. Pharmacol. 2012, 166, 510-521. [CrossRef]

19. Reilly, R.P.D.M. Inflammatory Mediators in Normal, Sensitive and Diseased Skin Types: Investigative Report. Acta Derm. Venereol. 2000, 80, 171-174. [CrossRef]

20. Reinert, P.; Rybojad, M.; Humbert, P.; De Belilovsky, C.; Homsi, M. PRO investigation: PRevalence and Origins of Hyper-sensitive skin among more than 8000 children. J. Am. Acad. Dermatol. 2010, 62 (Suppl. 1), AB113.

21. Yatagai, T.; Shimauchi, T.; Yamaguchi, H.; Sakabe, J.-I.; Aoshima, M.; Ikeya, S.; Tatsuno, K.; Fujiyama, T.; Ito, T.; Ojima, T.; et al. Sensitive skin is highly frequent in extrinsic atopic dermatitis and correlates with disease severity markers but not necessarily with skin barrier impairment. J. Dermatol. Sci. 2018, 89, 33-39. [CrossRef]

22. Nettis, E.; Ortoncelli, M.; Pellacani, G.; Foti, C.; Di Leo, E.; Patruno, C.; Rongioletti, F.; Argenziano, G.; Ferrucci, S.M.; Macchia, L.; et al. A Multicenter Study on the Prevalence of Clinical Patterns and Clinical Phenotypes in Adult Atopic Dermatitis. J. Investig. Allergol. Clin. Immunol. 2020, 30, 448-450. [CrossRef]

23. Serup, J. EEMCO guidance for the assessment of dry skin (xerosis) and ichthyosis: Clinical scoring systems. Skin Res. Technol. 1995, 1, 109-114. [CrossRef]

24. R Development Core Team. R: A Language and Environment for Statistical Computing; R (Version 4.0.0); R Development Core Team: Vienna, Austria; Available online: http:/ / www.R-project.org (accessed on 29 April 2020).

25. Bianchi, M.E. DAMPs, PAMPs and alarmins: All we need to know about danger. J. Leukoc. Biol. 2007, 81, 1-5. [CrossRef] [PubMed]

26. Akdis, M.; Aab, A.; Altunbulakli, C.; Azkur, K.; Costa, R.A.; Crameri, R.; Duan, S.; Eiwegger, T.; Eljaszewicz, A.; Ferstl, R.; et al. Interleukins (from IL-1 to IL-38), interferons, transforming growth factor $\beta$, and TNF- $\alpha$ : Receptors, functions, and roles in diseases. J. Allergy Clin. Immunol. 2016, 138, 984-1010. [CrossRef] [PubMed]

27. Bando, M.; Hiroshima, Y.; Kataoka, M.; Shinohara, Y.; Herzberg, M.C.; Ross, K.F.; Nagata, T.; Kido, J.-I. Interleukin-1 $\alpha$ regulates antimicrobial peptide expression in human keratinocytes. Immunol. Cell Biol. 2007, 85, 532-537. [CrossRef]

28. Steude, J.; Kulke, R.; Christophers, E. Interleukin-1-stimulated Secretion of Interleukin-8 and Growth-related Oncogene- $\alpha$ Demonstrates Greatly Enhanced Keratinocyte Growth in Human Raft Cultured Epidermis. J. Investig. Dermatol. 2002, 119, 1254-1260. [CrossRef] [PubMed]

29. Hirao, T.; Aoki, H.; Yoshida, T.; Sato, Y.; Kamoda, H. Elevation of Interleukin 1 Receptor Antagonist in the Stratum Corneum of Sun-exposed and Ultraviolet B-irradiated Human Skin. J. Investig. Dermatol. 1996, 106, 1102-1107. [CrossRef]

30. Falcone, D.; Spee, P.; Kerkhof, P.; Erp, P.E.J.V.; Van De Kerkhof, P.C.M. Minimally-invasive Sampling of Interleukin-1? and Interleukin-1 Receptor Antagonist from the Skin: A Systematic Review of in Vivo Studies in Humans. Acta Derm. Venereol. 2017, 97, 1066-1073. [CrossRef]

31. Terui, T.; Hirao, T.; Sato, Y.; Uesugi, T.; Honda, M.; Iguchi, M.; Matsumura, N.; Kudoh, K.; Aiba, S.; Tagami, H. An increased ratio of interleukin-1 receptor antagonist to interleukin-1? in inflammatory skin diseases. Exp. Dermatol. 1998, 7, 327-334. [CrossRef]

32. Perkins, M.A.; Osterhues, M.A.; Farage, M.A.; Robinson, M.K. A noninvasive method to assess skin irritation and compromised skin conditions using simple tape adsorption of molecular markers of inflammation. Skin Res. Technol. 2001, 7, 227-237. [CrossRef]

33. Tsuruta, J.; Sugisaki, K.; Dannenberg, A.M.; Yoshimura, T.; Abe, Y.; Mounts, P. The cytokines NAP-1 (IL-8), MCP-1, IL-1 beta, and GRO in rabbit inflammatory skin lesions produced by the chemical irritant sulfur mustard. Inflammation 1996, 20, $293-318$. [CrossRef]

34. Kondo, S.; Kono, T.; Sauder, D.N.; McKenzie, R.C. IL-8 Gene Expression and Production in Human Keratinocytes and Their Modulation by UVB. J. Investig. Dermatol. 1993, 101, 690-694. [CrossRef] [PubMed]

35. Yasuda, M.; Nishizawa, T.; Ohigashi, H.; Tanaka, T.; Hou, D.-X.; Colburn, N.H.; Murakami, A. Linoleic acid metabolite suppresses skin inflammation and tumor promotion in mice: Possible roles of programmed cell death 4 induction. Carcinogenesis 2009, 30, 1209-1216. [CrossRef] [PubMed]

36. Fritsche, K.L. Too much linoleic acid promotes inflammation-Doesn't it? Prostaglandins Leukot. Essent. Fat. Acids 2008, 79, 173-175. [CrossRef] [PubMed]

37. Innes, J.K.; Calder, P.C. Omega-6 fatty acids and inflammation. Prostaglandins Leukot. Essent. Fat. Acids 2018, 132, 41-48. [CrossRef] [PubMed]

38. Johnson, G.H.; Fritsche, K. Effect of Dietary Linoleic Acid on Markers of Inflammation in Healthy Persons: A Systematic Review of Randomized Controlled Trials. J. Acad. Nutr. Diet. 2012, 112, 1029-1041.e15. [CrossRef] [PubMed]

39. Khnykin, D.; Miner, J.H.; Jahnsen, F. Role of fatty acid transporters in epidermis. Derm.-Endocrinol. 2011, 3, 53-61. [CrossRef]

40. Jang, H.-Y.; Koo, J.-H.; Lee, S.-M.; Park, B.-H. Atopic dermatitis-like skin lesions are suppressed in fat-1 transgenic mice through the inhibition of inflammasomes. Exp. Mol. Med. 2018, 50, 1-9. [CrossRef] 
41. Sala-Vila, A.; Miles, E.A.; Calder, P. Fatty acid composition abnormalities in atopic disease: Evidence explored and role in the disease process examined. Clin. Exp. Allergy 2008, 38, 1432-1450. [CrossRef]

42. Johnson, M.; Bradford, C. Omega-3, Omega-6 and Omega-9 Fatty Acids: Implications for Cardiovascular and Other Diseases. J. Glycom. Lipidom. 2014, 4, 2153-0637. [CrossRef]

43. Ziboh, V.A.; Miller, C.C.; Cho, Y. Metabolism of polyunsaturated fatty acids by skin epidermal enzymes: Generation of antiinflammatory and antiproliferative metabolites. Am. J. Clin. Nutr. 2000, 71, 361s-366s. [CrossRef] [PubMed]

44. Patterson, E.; Wall, R.; Fitzgerald, G.F.; Ross, R.P.; Stanton, C. Health Implications of High Dietary Omega-6 Polyunsaturated Fatty Acids. J. Nutr. Metab. 2012, 2012, 1-16. [CrossRef] [PubMed]

45. Stamatas, G.; Morello, A.; Mays, D. Early Inflammatory Processes in the Skin. Curr. Mol. Med. 2013, 13, 1250-1269. [CrossRef]

46. Fluhr, J.; Lachmann, N.; Baudouin, C.; Msika, P.; Darlenski, R.; De Belilovsky, C.; Bossert, J.; Colomb, E.; Burdin, B.; Haftek, M. Development and organization of human stratum corneum after birth: Electron microscopy isotropy score and immunocytochemical corneocyte labelling as epidermal maturation's markers in infancy. Br. J. Dermatol. 2014, 171, 978-986. [CrossRef] 